\title{
Research on the Construction of Online Culture Trading Platform Based on Netizens' Wishes
}

\author{
Ren SONG, Weiwei WANG,', Yang LIU \\ Jilin University of Finance and Economics, Jilin, China
}

\begin{abstract}
According to the statistical data of the 44th China statistical report on Internet development, as of June 2019, the number of Internet users in China has reached 854 million, and the penetration rate has reached $61.2 \%$. The number of mobile Internet users reached 8.47 million, accounting for $99.1 \%$ of the total Internet users [1]. The number of Internet users in China continued to grow steadily. With the rapid development of high-tech and Internet, the continuous expansion of Internet users, the continuous optimization of the network environment, the gradual formation of the network society, the network life tends to be a regular state, and the network culture is also formed in this environment, which has become an important part of China's cultural system. This paper takes netizens as the core, studies the construction of network cultural data trading platform based on netizens' behavior. Through the establishment of netizens influence model and online cultural data trading platform, this paper studies the consumption intention of online cultural products and the characteristics of online cultural data trading platform from the perspective of netizens. Based on the data of strong research results, this paper puts forward suggestions and strategies for the construction of network cultural data trading platform and the innovation of network cultural products in China.
\end{abstract}

Keywords. Network culture, network culture data, trading platform, network communication, network culture development

\section{Introduction}

Network culture is a kind of cultural form. It takes the network as the medium, the network platform as the carrier, and the culture as the core. Relying on the production and development of high-tech and network technology, it uses certain forms of language, sound and video to spread ideas and culture, express ideas, views, emotions and consciousness. It constructs a new way of Ideological and cultural expression, which influences and changes people's life style, production mode and values [2].

With the rise of network culture, its related production, circulation, service and other links and departments constitute a complex network culture industry [3]. In recent years, its industrial scale has been expanding. In the whole network culture industry chain, the network culture takes the network culture data transaction platform as the carrier, takes the network culture product as the ultimate goal performance. There are a variety of

\footnotetext{
${ }^{1}$ Corresponding Author, Information Management Center, Jilin University of Finance and Economics, Jilin, China, 23392147@qq.com.
} 
network cultural products, including online literature, online games, online video, online music, etc.

With the increasing abundance of network cultural products, the supply capacity has been significantly enhanced. However, compared with traditional cultural products, consumers' willingness to consume online cultural products is significantly different. Ren Xianliang, deputy director of the office of the central leading group on network security and information and deputy director of the national Internet Information Office, pointed out: to develop network culture, we should strengthen the supply and dissemination of excellent network cultural products, build a platform for network cultural exchange and communication, and share the development of network culture [4], not only from the macro level of politics, system, economy and supervision, but also from the macro level from the perspective of fundamental development. As the carrier of network culture products, network culture data trading platform is the main way of network culture spreading in cyberspace. Its platform features directly affect consumers' online cultural consumption intention products. Therefore, strengthening the construction of network culture data trading platform is of great significance to improve the network culture industry and promote the prosperity and development of network cultural products.

\section{Literature review}

On the construction of network culture, many scholars put forward different views. Some scholars think that the root cause of the problems in the development of network culture is the lack of government support. The government should take effective measures to promote the development of network culture industry. Some scholars think that the negative effects of technological development will have a certain impact on network culture. Some scholars think that the development and management of network culture industry should pay attention to the strategic level. Some scholars advocated to encourage cultural innovation to realize the benign evolution of the industry. Some scholars think that the role of media in the network culture industry ecosystem is becoming more and more important. In the digital era, it is very important to play the main role of media. Network culture data trading platform is the carrier of network culture display and dissemination, the platform of government support and technical support, and the platform of innovation, strategic development and product operation of the whole network culture industry. Therefore, it is of great practical significance to study the network culture data trading platform and its application. Some scholars think that Internet users, as consumers, have become the core subject of wireless potential release of network culture industry, participate in the innovation process of network cultural products, and improve the innovation ability of network cultural products. Therefore, from the perspective of consumers, the construction of network culture is of great significance.

At present, the research on network culture in China is mostly carried out from three aspects: system supervision, risk system and industrial scale. However, from the perspective of consumer intention, there is little literature on the Internet. This paper focuses on netizens, from the perspective of netizens' wishes, studies the network cultural data trading platform and network cultural products, which is innovative. 


\section{Research method}

\subsection{Construction of network culture data trading platform including netizens influence model}

The network culture data trading platform is an important part of the network culture industry chain. It is the carrier of network cultural products, and also the platform of spreading and trading network cultural products. If it is an excellent trading platform, it can promote the development and exchange of network culture, and also can promote the survival of the fittest of network cultural products. Like other shopping platforms, online cultural data platform is a trading platform with all the characteristics of the trading platform, which will have a certain impact on the use intention of the Internet. According to the theory of SOR (stimulus organization response), the receiver of external factors will produce conscious or unconscious psychological reactions (including emotional response or cognitive response). After experiencing a series of psychological reactions, the subjects have a certain degree of behavioral response to stimulation [5]?

Through the comparative analysis and in-depth study of many network cultural data trading platforms, this paper divides the characteristics of network data trading platforms into knowledge, economy, interaction, entertainment, vision, personalization and security. Through the stimulation of the characteristics (stimulus factors) of the network data trading platform, it can trigger the internal emotional response of Internet users, including the sense of pleasure and the perception of awakening, and then generate the willingness of Internet users. The characteristic variables of the network culture data trading platform are described in Table 1.

Table 1: main dimensions of characteristic variables of online cultural data trading platform

\begin{tabular}{|c|c|}
\hline Variable name & Variable definition \\
\hline knowledge & $\begin{array}{l}\text { The richness and clarity of product related subject information and non- } \\
\text { product related peripheral information provided by the platform }\end{array}$ \\
\hline Economics & $\begin{array}{l}\text { The platform provides consumers with real economic perceived benefits such } \\
\text { as product price, price discount and promotion }\end{array}$ \\
\hline Interaction & $\begin{array}{l}\text { The platform uses the Internet and modern technology to interact with } \\
\text { participants }\end{array}$ \\
\hline Entertainment & $\begin{array}{l}\text { As a kind of media, the platform provides animation, video and other } \\
\text { entertainment functions for netizens }\end{array}$ \\
\hline Visually & How attractive is the external form of the platform interface \\
\hline individualization & $\begin{array}{l}\text { The platform provides efficient, valuable and targeted services for consumers } \\
\text { according to their preferences and behaviors }\end{array}$ \\
\hline security & $\begin{array}{l}\text { The security degree of the platform for netizens ' information, privacy } \\
\text { protection and payment process }\end{array}$ \\
\hline inspire & $\begin{array}{l}\text { The degree to which an individual feels stimulation, excitement, excitement } \\
\text { and surprise in a particular situation }\end{array}$ \\
\hline Pleasant & $\begin{array}{l}\text { The degree to which an individual is satisfied, happy, happy and comfortable } \\
\text { in a given situation }\end{array}$ \\
\hline Willing to use platform & The subjective will of netizens to use Internet cultural data trading platform \\
\hline
\end{tabular}

The construction of network data trading platform not only includes the construction of its own platform, but also includes the innovative products of network culture and the consumers' willingness to treat the network cultural products. It is a quantitative index product for us to study the network culture. Online cultural products are intangible products. Consumers have no standard judgment of them. They often rely on their own perception to decide whether to spend or not. Therefore, this study uses perceived value to judge consumers' online cultural consumption intention products. Based on the SOR theoretical model, consumers' perceived response to online 
consumption, that is, after generating perceived value, will produce consumption intention. The characteristics of network cultural products are explained in Table 2.

Table 2: the first dimension of the characteristic variables of network cultural products

\begin{tabular}{|c|c|}
\hline Variable name & Variable definition \\
\hline Ease of use & $\begin{array}{l}\text { The extent to which consumers think that online cultural products are easy to } \\
\text { use }\end{array}$ \\
\hline Perceived usefulness & $\begin{array}{l}\text { Consumers think that the functional benefits brought by network cultural } \\
\text { products }\end{array}$ \\
\hline $\begin{array}{l}\text { Perceptual } \\
\text { Entertainment }\end{array}$ & $\begin{array}{l}\text { The degree of emotional pleasure consumers get from using Internet cultural } \\
\text { products }\end{array}$ \\
\hline Perceived cost & $\begin{array}{l}\text { Consumers' willingness to pay for online cultural products is the perception of } \\
\text { price rationality }\end{array}$ \\
\hline Perceived risk & $\begin{array}{l}\text { Consumers' subjective prediction of various losses and uncertainties caused by } \\
\text { the purchase and use of online cultural products }\end{array}$ \\
\hline Perceived value & $\begin{array}{l}\text { On the basis of perceived profit and loss, consumers' overall evaluation of the } \\
\text { benefits brought by network cultural products }\end{array}$ \\
\hline Consumption intention & Consumers' subjective willingness to purchase and use online cultural products \\
\hline
\end{tabular}

Network culture data trading platform is the carrier of network culture, and network culture is finally displayed through network culture products [6]. As the terminal of network culture industry chain, network cultural products directly face Internet users. At the same time, Internet users' willingness to consume online cultural products will also be affected by the use of online cultural data trading platform. Based on the above theory, this paper constructs a relationship model between the willingness and impact of netizens using cultural data trading platform, as shown in Figure 1.

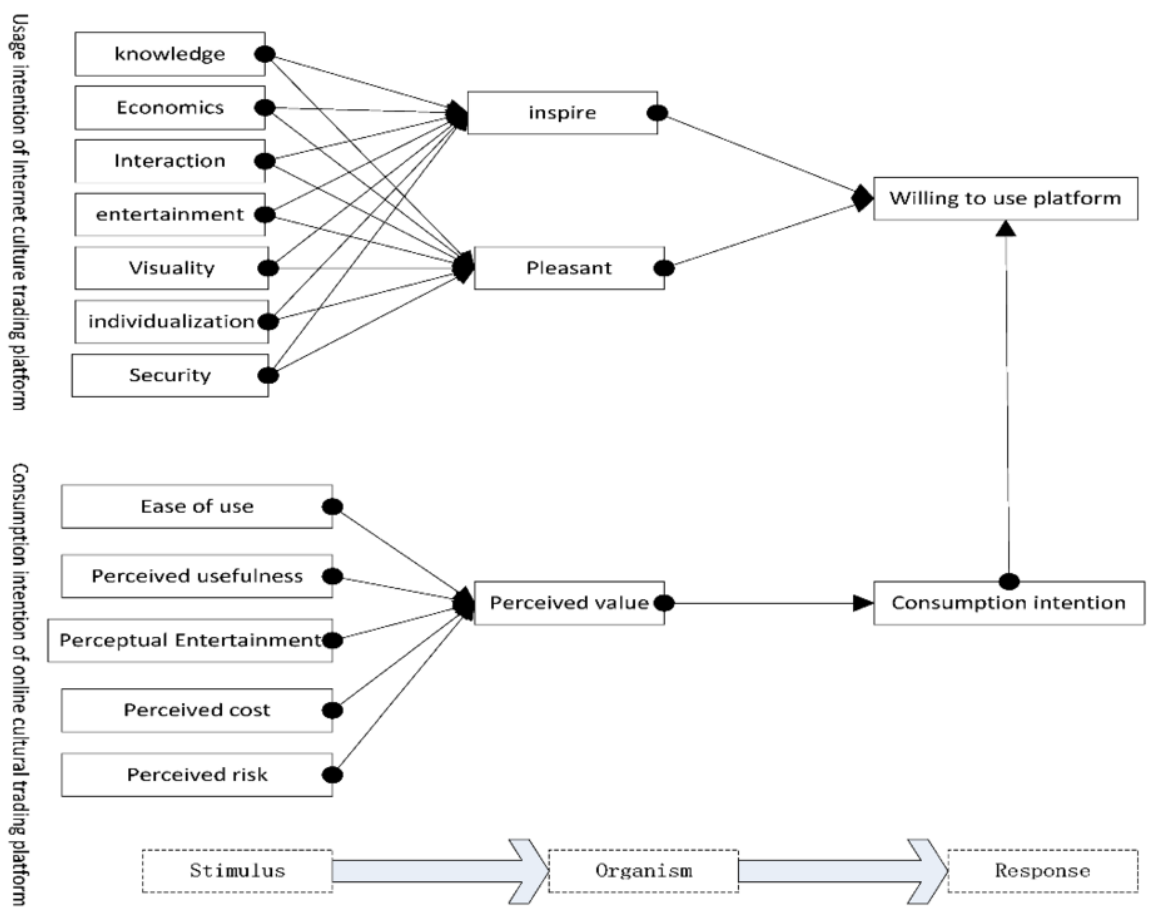

Figure 1 Influence Model of netizens' willingness on online cultural data trading platform 


\subsection{Construction strategy of Internet cultural data trading platform based on Netizens' wishes}

According to the influence model of netizens' willingness of online cultural data trading platform, this paper studies the influence of network cultural data trading platform characteristics on Internet users' consumption intention, the influence of network cultural product characteristics on Internet users' consumption intention, and the influence of Internet users' consumption intention on Internet cultural data trading platform. According to the survey results, based on the wishes of netizens, this paper puts forward the construction and development strategy of online cultural data trading platform.

\section{Academic value and application value}

Based on the SOR theory, this paper constructs a model of the influence of Internet users' willingness on the Internet cultural data trading platform, which is mainly measured from three aspects, including the influence of the characteristics of the network cultural data trading platform on the Internet users' willingness, the influence of the characteristics of the network cultural products on the Internet users' willingness to consume, the influence of the network users' consumption intention and the network transaction.

According to the influence model of netizens' willingness on online cultural data trading platform, this paper systematically analyzes the definition of main variables. Through the research design and empirical analysis, the research results are obtained, and the research results are discussed and analyzed. Finally, it summarizes the construction strategy of online cultural data trading platform based on Netizens' wishes.

Based on the SOR theory, this paper constructs a model of the influence of netizens on the willingness of online cultural data trading platform, and verifies the model with the method of empirical analysis. On the basis of ensuring the theoretical basis of the model, reliable and effective data are collected through questionnaire survey, as well as the influence of the characteristics of online cultural data trading platform on Netizens' willingness to use, the influence of network cultural product characteristics on Internet users' consumption intention and the influence on the use intention of network cultural data trading platform, which provides a powerful strategy for the development of network cultural data transaction construction and data support. The research method of this paper is more objective than qualitative research.

According to the survey results of netizens' willingness on online cultural data trading platform, this paper puts forward the construction and development strategy of online cultural data trading platform based on Netizens' willingness, which provides a new perspective for the construction of online cultural data trading platform.

\section{Conclusion}

Based on the systematic analysis and literature review of network culture and its industry development in recent years, this paper studies the construction of network culture data trading platform based on Internet users. Just like the carrier of network cultural products and effective communication channels, network cultural data trading platform plays an important role in the development of the network. In this paper, starting from the Internet 
users' willingness to consume network cultural products and the characteristics of network culture platform, starting from the construction of network culture data trading platform, this paper discusses the construction of network culture data trading platform, opens up a new perspective of network culture research, and further enriches the research content in the field of network culture.

From the perspective of netizens, this paper studies the consumption intention of online cultural products and the characteristics of online cultural data trading platform. The research results provide theoretical basis for the construction of network data trading platform and the innovation of network cultural products, and provide data support for the improvement of network culture industry system. It is helpful for network culture enterprises to improve marketing strategy, develop new network culture products, improve data trading platform of network culture, and develop Chinese network culture.

\section{Acknowledgement}

This paper is supported by Project of the Department of science and technology of Jilin Province, Research on the Countermeasures of artificial intelligence in the development of innovative education. (Contract number: 20200101084FG). The Education Department of Jilin Province, Research on the influence of intelligent robot in innovation education in Jilin Province. (Contract number: JJKH20210132KJ). The Education Department of Jilin Province, Research on the application of big data technology in the construction of smart campus. (Contract number: JJKH20200142KJ). The Education Department of Jilin Province, Path design and implementation of intelligent financial management in colleges and universities in Jilin Province under the background of artificial intelligence. (Contract number: JJKH20210134KJ). Jilin Province Higher Education Association's 2019 project, Research on the Construction of Entrepreneurship Education Ecosystem and Support System in Colleges and Universities. (No.: JGJX2019D270). Jilin Province Social Science Foundation Project, Research on the Evaluation and Optimization Strategy of the Coordinated Development of Cultural Resources and Tourism Industry in Jilin Province. (No.: 2020C053). The project of teaching reform on higher education in Jilin Province: Practice and research on ideology and politics teaching of network information security course. (No.: JLSI680620190723162538).

\section{References}

[1] China Internet Network Information Center (CNNIC) in 《The 44th China Statistical Report on Internet Development $\rangle$

[2] Zhu Ruihai. Research on the dual effects and Countermeasures of network culture [J]. People's forum, 2013(6):174-176.

[3] Bai Shuying. Outlook on the development of network culture with Chinese characteristics and its theoretical significance [J]. Marxist studies, 2012, 000 (003): 77-82.

[4] Wang Xingxing, Xie zongxiao. Information Security Management Series II. Information security: the perspective of national strategy [J]. China Quality and standards guide, 2015 (3): 30-32.

[5] Xu Yue. Research on the influence of information publicity on College Students' habitual energy-saving behavior intention [D].

[6] Chen Lanlan. Research on the logical construction and survival path of the ecological field of network culture [D]. 2017. 